\title{
Assessment of Knowledge, Attitude, and Practice in respect of Medical Waste Management among Healthcare Workers in Clinics
}

\author{
Pensiri Akkajit $\mathbb{D}^{1,2,3}$ Husna Romin, ${ }^{1}$ and Mongkolchai Assawadithalerd ${ }^{3}$ \\ ${ }^{1}$ Faculty of Technology and Environment, Prince of Songkla University, Phuket Campus, Phuket 83120, Thailand \\ ${ }^{2}$ Environmental Research Institute, Chulalongkorn University, Bangkok 10330, Thailand \\ ${ }^{3}$ Research Program, \\ The Development of Management System for Reduction and Control of Water Contamination and Distribution, \\ Songkhla Lake Basin and the Western Coastline of the South of Thailand, \\ Center of Excellence on Hazardous Substance Management (HSM), Bangkok 10330, Thailand
}

Correspondence should be addressed to Pensiri Akkajit; pensiri.a@phuket.psu.ac.th

Received 21 April 2020; Revised 31 July 2020; Accepted 14 September 2020; Published 28 September 2020

Academic Editor: Issam A. Al-Khatib

Copyright ( $\odot 2020$ Pensiri Akkajit et al. This is an open access article distributed under the Creative Commons Attribution License, which permits unrestricted use, distribution, and reproduction in any medium, provided the original work is properly cited.

Medical waste represents a significant health risk and an environmental pollution concern due to its hazardous characteristics. The knowledge and practice of healthcare personnel in respect of the disposal of medical waste is essential to perform effective medical waste management. Therefore, the aim of this study was to assess the knowledge, attitudes, and practices related to medical waste management among healthcare workers in clinics (medical and dental clinics, specialized medical, laboratory clinics, polyclinics, and midwifery clinics) in Phuket, Thailand. A cross-sectional study was designed with stratified-random sampling used to select the sample of 344 respondents from 172 clinics of which data were collected using face-to-face interviews. The results showed that the majority of respondents (87.2\%) were female of whom $36.9 \%$ were aged (20-29), 52.0\% had more than 5 years working experience, and $51.2 \%$ had participated in at least one training course regarding medical waste management. The overall scores for knowledge, attitude, and practice were at a high level (89.5\%, 91.9\%, and 92.2\%, respectively). Significant and positive correlations were found between knowledge and attitude $(r=0.464)$, knowledge and practice $(r=0.396)$, and practice and attitude $(r=0.519)$. Statistical analysis using $t$ tests and one-way analysis of variance showed that working experience and its duration were significant factors influencing good medical waste management practice. However, local authorities should implement a well-planned collection and transfer process for medical waste in order to reduce the risk of environmental pollution and the risk of infection or injury to healthcare workers and the general public.

\section{Introduction}

Medical waste is generated by healthcare facilities such as hospitals, clinics, blood banks, and laboratories, which may cause infection to any person coming into contact with it. This may consist wholly or partly of human or animal tissue, blood or other body fluids, excretions, drugs or pharmaceutical products, swabs or dressings, syringes, and needles or other sharp instruments. It is waste which unless rendered safe may prove hazardous to any person coming into contact with it [1-3]. Therefore, medical waste can be considered as being of the greatest environmental concern since it can harbor potentially harmful microorganisms and carries the risk of transmission of infections from healthcare facilities to healthcare workers, patients, and general public. In order to prevent harmful consequences to the human health, the community, and the environment, proper medical waste management (MWM) is needed, which entails managing waste from their generation, through separation, collection, transport, and treatment, to their final disposal [4-6]. In many developing countries, MWM is not properly carried out, and there are no clearly defined regulations and a lack of operational standards $[7,8]$. It has been reported that the disposal of medical waste mixed with municipal solid waste is likely to occur in clinics due to the small quantity of medical waste generated, the high cost of collection and disposal, and a lack of 
enforcement from the local authorities [9]. Phuket, the largest island in the southern part of Thailand, is a very famous and popular tourist destination [10]. The number of tourists visiting Phuket is significant, and this affects the amount of waste generation. It has been reported that the amounts of medical waste generated from hospitals and clinics are approximately $1,200 \mathrm{~kg} /$ day and $1.32 \mathrm{~kg} /$ day, respectively [11]. Phuket's waste generation currently exceeds its capacity for waste disposal, and the island has limited waste management options since the amount of waste generated continually increases. At present, MWM in Phuket is conducted at the hospital level, and the final destination for medical waste is an infectious-materials incinerator for the treatment of medical waste that is regulated by the Thailand Public Health Act and WHO Guidelines and managed by Phuket City Municipality under the supervision of the Board of solid waste management and wastewater of Phuket Province. However, this service is only available for hospitals [12]. Therefore, the mismanagement of medical waste in clinics may represent a significant risk factor for disease transmission even though the amount of infectious waste in clinics is less significant than that from hospitals. However, the lack of appropriate waste management options for clinics can cause a variety of adverse impacts on the communities they serve such as infection transmission and soil and water contamination. Lack of knowledge about waste segregation and waste collection, lack of risk awareness, unsafe waste disposal, and limited financial resources are the key factors that cause the mismanagement of infectious waste. Moreover, healthcare workers are the key personnel responsible for the medical waste management from generation until their final disposal [13]. Therefore, the aim of this study was to assess the knowledge, attitude, and practice (KAP) of MWM among healthcare workers in clinics located in Phuket Province in southern Thailand. The results will provide information regarding the current situation and problems relating to MWM in clinics and will assist the future planning of MWM at Phuket, Thailand.

\section{Materials and Methods}

2.1. Study Area and Study Design. There are three administrative districts in Phuket, namely, Mueang Phuket district, Kathu district, and Thalang district. According to the Bureau of Environmental Health, Department of Health, Ministry of Public Health, Thailand (2017), there are 383 healthcare facilities in Phuket, comprising 6 hospitals, 21 subdistrict health promoting hospitals, and 328 clinics. In this study, the population consisted of all the clinics located in Phuket, except 17 physical therapy and Thai traditional clinics $(N=311)$. The size of the sample was calculated using the Taro Yamane formula [14] with a 95\% confidence level. Based on that, the number of clinics included in this study was $172(n=172)$. Moreover, a stratified sampling technique was employed to select the type of clinics which made up the sample, which consisted of medical clinics $(n=76)$, dental clinics $(n=55)$, specialized medical clinics $(n=32)$, laboratory clinics $(n=6)$, polyclinics $(n=2)$, and midwifery clinics $(n=1)$. The location of the 172 clinics sampled is illustrated (Figure 1) showing all the sampling locations, which were Mueang Phuket district $(n=121)$, Kathu district $(n=33)$, and Thalang district $(n=18)$. The data were collected by face-to-face interviews with healthcare workers in the 172 clinics between May and July, 2017. Two healthcare workers were selected to be interviewed from each clinic and were those mainly involved in the generation, segregation, and management of medical waste, including doctors, dentists, medical assistants, dentist's assistants, nurses, laboratory scientists, and medical receptionists. Therefore, the total number of respondents in this study was 344 $(2 \times 172$ clinics $)$. The interviews were conducted based on a survey questionnaire, which was designed based on a literature review and the questionnaire was pretested in order to improve the questions. This study was approved by the local Ethics Committee of the Phuket Provincial Public Health Office, Ministry of Public Heath, Thailand. Informed and written consent to participate in the study was obtained by the participants. An explanation of the purpose of research, extent of confidentiality of personal identification, and demographic data were offered to all included participants. The validity and reliability of the section of the questionnaire dealing with knowledge of MWM were tested using the Kuder-Richardson formula 20 (KR-20), while that relating to attitudes and practice in handling medical waste was tested with Cronbach's coefficient alpha [15].

2.2. Methods of Measurement. A questionnaire was used in this study to determine the KAP of MWM among healthcare personnel in the selected clinics, which was the primary data with secondary data being obtained from the Bureau of Environmental Health, Department of Health. The questionnaire contained both open-ended and closed-ended items and was divided into five parts as follows: part A: sociodemographic characteristics of the respondents; part B: general information from respondents regarding MWM at clinics; part C: knowledge of respondents about MWM (K); part D: attitudes of respondents towards MWM (A); and part E: practice of respondents in respect of MWM (P). In each part, the items were designed to elicit information about the respondents' KAP relating to four aspects of medical waste: (1) segregation, (2) collection, (3) transportation, and (4) final disposal. Details of the items in the questionnaire used to obtain information about those four aspects were as follows:

(1) Knowledge of MWM (K) was assessed using 16 items, such as follows: infectious/medical waste and general waste cannot be handled and disposed of together; the quantity of infectious/medical waste in the container or bag should render the bag $1 / 3$ to $2 / 3$ full; and medical waste containers must be closed containers. The knowledge items were scored as either " 1 " or " 0 " for the correct or incorrect response, respectively. The total knowledge score for each respondent could range from 0 to 16 .

(2) Attitude towards MWM (A) was assessed using 10 items, such as follows: We consider it necessary to handle medical waste more cautiously. A 3-point Likert scale was used to respond to the items in the 


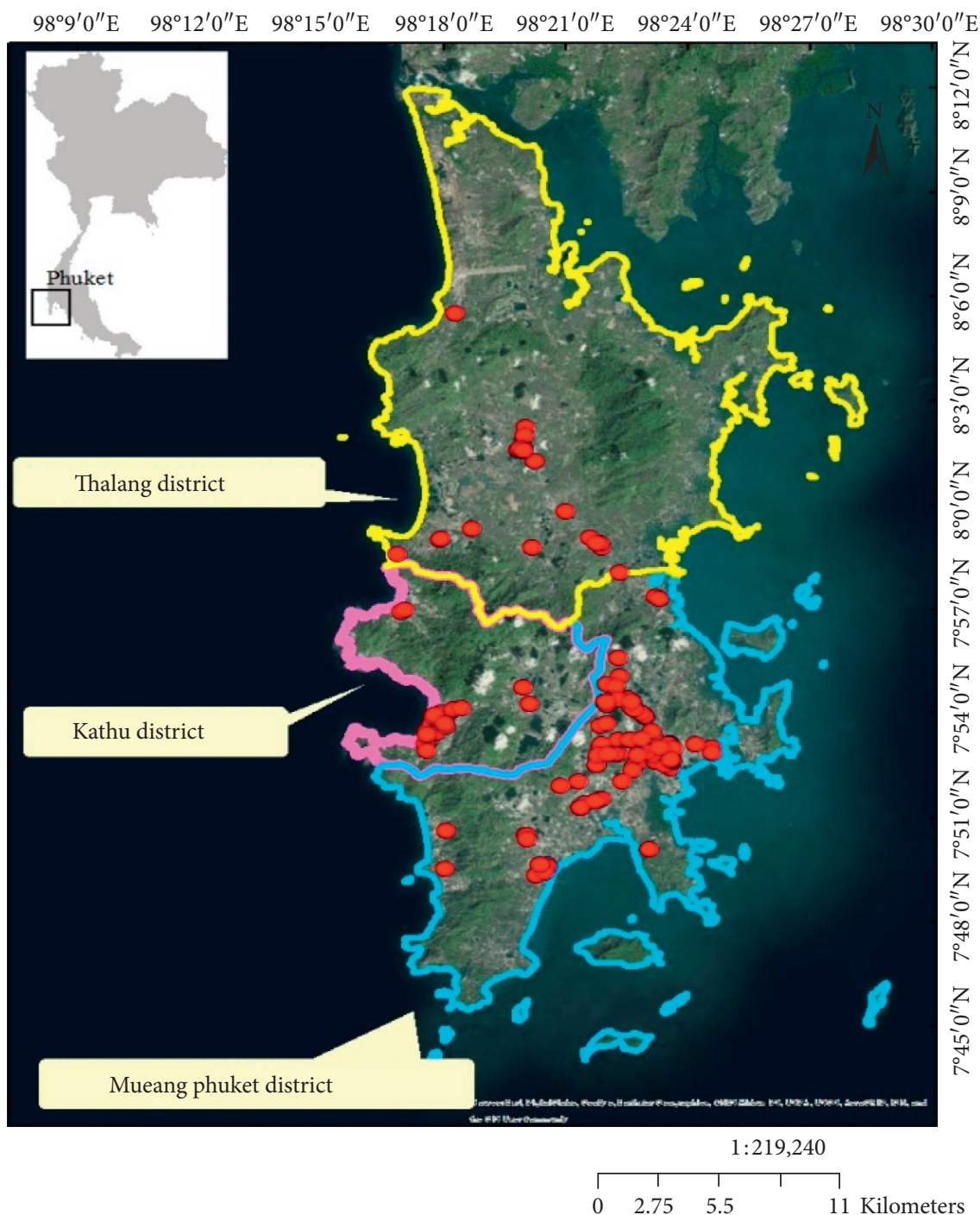

Clinic sampling locations

Figure 1: Geographical location of the study area (Phuket Province, Thailand) and the locations of the clinics making up the research sample.

attitude section where "agree," "undecided," and "disagree" were scored as 2, 1, and 0, respectively. The total attitude score for each respondent could range from 0 to 20 .

(3) Practice in respect of MWM (P) was assessed with 12 questions, such as follows: how often do you separate noninfectious waste from general waste? and how often do you wear gloves while handling infectious/ medical waste? The participants were asked to respond to these questions based on a 3-point Likert scale, where "always," "sometimes," and "never" were scored as 2, 1, and 0 , respectively. The total practice score for each respondent could range from 0 to 24 .

2.3. Classification of KAPScores. The scores of the individual respondents in respect of knowledge about MWM were classified into "high" and "low" categories, while the attitude scores were classified as either "positive" and "negative," and the practice scores was classified as either "good" or "poor" using the median score for each of the KAP items/questions. The individual knowledge, attitude, and practice scores for each respondent were then aggregated, with high, positive, and good scores being represented by + , while low, negative, and poor scores were represented by -. Then, the aggregated KAP scores were classified into eight possible groups as described by Aluko et al. [16]. The mean score for each item was computed by dividing the overall KAP score from all the respondents by the number of respondents $(n=344)$ and was expressed as percentages. These scores were then categorized into low, medium, and high levels (Table 1).

2.4. Statistical Analysis. Statistical analyses were performed to investigate the associations between demographic information and the knowledge, attitude, and practice scores of the personnel in respect of MWM, using independent $t$ 
TABLE 1: Interpretation of the mean KAP item scores in this study.

\begin{tabular}{ll}
\hline Questionnaire & Interpretation method \\
\hline Part A: sociodemographic characteristics & (i) Checklist: a list of items to-tick-off \\
Part B: general information of the MWM & (i) Low if scores $<33 \%$ \\
\hline Part C: knowledge of MWM & (ii) Medium if scores $33-66 \%$ \\
Part D: attitudes towards MWM & (iii) High if scores $>66 \%$ \\
Part E: practice in respect of MWM & $(+,+,+)$ \\
\hline Categorization of the scores for KAP & $(-,-,-)$ \\
High K, positive A, and good P & $(+,+,-)$ \\
Low K, negative A, and poor P & $(+,-,-)$ \\
High K, positive A, and poor P & $(+,-,+)$ \\
High K, negative A, and poor P & $(-,+,+)$ \\
High K, negative A, and good P & $(-,-,+)$ \\
Low K, positive A, and good P & $(-,+,-)$ \\
Low K, negative A, and good P & \\
Low K, positive A, and poor P & \\
\hline
\end{tabular}

tests, one-way analysis of variance (ANOVA), and Pearson correlation coefficients. All statistical analyses were conducted using the SPSS version 23.0 software package at a level of significance of $95 \%$.

\section{Results and Discussion}

3.1. Part A: Sociodemographic Characteristics of the Respondents. Two healthcare workers from each of the 172 clinics, consisting of one doctor and one staff member, were selected randomly and included in this study. The results revealed that the majority of the 344 respondents were female $(87.2 \%)$ with the most common age range being 20-29 years old (36.9\%). Most of respondents held at least bachelor's degree, and the most common duration of working experience was more than 5 years. The major occupation groups of the respondents comprised medical assistants/nurses/laboratory scientists with experience of handling medical waste in their clinics and had participated in MWM training (Table 2).

3.2. Part B: General Information from Respondents regarding MWM at Clinics. The general information about MWM given by the respondents is presented in Table 3. It was found that the majority of the clinics in this study were medical clinics with the amount of medical waste generated reported to be less than 1 kilogram/day. The main categories of medical waste generated in respective clinics were used needles and infectious contaminated cotton wool (Figure 2).

Many respondents generally disposed medical waste into the community's municipal solid waste bin located on a public road while few did not know how to dispose medical waste (Table 3 ).

From the information obtained, it can be seen that the waste generated in the clinics were not properly handled and could cause the spread of biological agents that represents risk for infection to the community and also the risk to contaminate the environment. The act of disposing own medical waste in the general waste bin, the contents of which would not undergo sufficiently high-temperature incineration to inactivate the microbial content, and insufficient heating at the municipal incinerator may cause further environmental problems due to those pathogens. In addition, there is a chance that scavengers who search for materials with a residual value, such as plastic bottles and cans, in the community's municipal solid waste bin, may suffer accidental injury caused by hazardous needles or sharps if the municipal waste contains medical waste. The results of this study were similar to the findings of Pandit et al. [17] who discovered that most hospitals in Bhopal, India, disposed their waste by open-air burning (83\%) and that more than $10 \%$ of medical waste was dumped in open fields without pre-treatment. Further, the study of Yong-Chul et al. [18] also showed that medical waste in Korea was often mixed with municipal solid waste, and it is evident that some countries still follow unsafe disposal systems. Thus, appropriate clinical waste management systems should be adopted and implemented to improve MWM.

3.3. Part C: Knowledge of Respondents about MWM (K). It is generally known that healthcare workers' knowledge about MWM is fundamental for proper MWM and is the most important aspect according to Vaught [19]. The respondents' knowledge was categorized into four different groups based on the respondents' occupations (see Table 4). According to the results, a high percentage of the respondents used color coding to identify and classify waste, which indicated a high level of understanding of MWM. Correct responses to the items: Material contaminated with body fluid is medical waste, The color coding for medical waste is red, and Sharp medical waste must be discarded into a hard container were given by $95.3 \%, 96.5 \%$, and $99.4 \%$, respectively. The results of this study were consistent with those from the study of Abdullah and Al-Mukhtar [20] which found that $79.2 \%$ of the respondents at hospitals in Mosul, Iraq used the correct color coding to properly identify medical waste. On the other hand, large numbers of the respondents in this study had incorrect knowledge about the transport and final disposal of medical waste $(47.7 \%$ and $60.2 \%$, respectively). This contrasted with the study of Singh et al. [21] which found that the majority of doctors (83.3\%), paramedics $(80 \%)$, and medical students $(66.7 \%)$ at King 
TABLE 2: Sociodemographic characteristics of respondents $(n=344)$.

\begin{tabular}{|c|c|c|c|}
\hline Variables & Frequency $(n)$ & Percentage (\%) & $P$ value \\
\hline \multicolumn{4}{|l|}{ Gender of respondents } \\
\hline Male & 44 & 12.8 & 0.342 \\
\hline Female & 300 & 87.2 & \\
\hline \multicolumn{4}{|c|}{ Age range of respondents (years) } \\
\hline$<20$ & 6 & 1.7 & 0.107 \\
\hline $20-29$ & 127 & 36.9 & \\
\hline $30-39$ & 122 & 35.5 & \\
\hline $40-49$ & 66 & 19.2 & \\
\hline$>49$ & 23 & 6.7 & \\
\hline \multicolumn{4}{|l|}{ Educational qualification } \\
\hline $\begin{array}{l}\text { Below bachelor's } \\
\text { degree }\end{array}$ & 111 & 32.3 & 0.717 \\
\hline Bachelor's degree & 192 & 55.8 & \\
\hline $\begin{array}{l}\text { Master's or doctoral } \\
\text { degree }\end{array}$ & 41 & 11.9 & \\
\hline \multicolumn{4}{|l|}{ Occupation of respondents } \\
\hline Doctor/dentist & 48 & 14.0 & 0.850 \\
\hline $\begin{array}{l}\text { Medical assistant/ } \\
\text { nurse/laboratory } \\
\text { scientist }\end{array}$ & 213 & 61.9 & \\
\hline Medical receptionist & 63 & 18.3 & \\
\hline $\begin{array}{l}\text { Others (such as owner, } \\
\text { cleaner, and dispenser) }\end{array}$ & 20 & 5.8 & \\
\hline \multicolumn{4}{|l|}{ Years of working experience } \\
\hline$<2$ & 69 & 20.1 & $0.001^{*}$ \\
\hline $2-5$ & 96 & 27.9 & \\
\hline$>5$ & 179 & 52.0 & \\
\hline \multicolumn{4}{|l|}{ Experience in MWM } \\
\hline Yes & 252 & 73.3 & $0.009^{*}$ \\
\hline No & 92 & 26.7 & \\
\hline \multicolumn{4}{|l|}{ Training in MWM } \\
\hline Yes & 176 & 51.2 & 0.180 \\
\hline No & 168 & 48.8 & \\
\hline
\end{tabular}

*Significant 0.05 .

TABLE 3: General information about clinical waste management at the respondents' clinic.

\begin{tabular}{lcc}
\hline Variables & Frequency $(n)$ & Percentage $(\%)$ \\
\hline Type of clinic & & 150 \\
Medical clinic & 64 & 111 \\
Specialized medical clinic & 3 & 18.6 \\
Dental clinic & 12 & 32.2 \\
Midwifery clinic & 4 & 3.9 \\
Laboratory clinic & & 1.2 \\
Polyclinic & 237 \\
\hline Quantity of medical waste in clinic & 78 \\
$<1$ kilogram/day & 9 \\
1-2 kilograms/day & 9 \\
2-3 kilograms/day & 5 \\
3-4 kilograms/day & 6 \\
4-5 kilograms/day & \\
\hline Medical waste disposal method at clinic & 30 \\
Do not know & 98 \\
Hire private infectious waste management company & 18 \\
Take to hospital & 74 \\
Take to infectious incinerator myself & 124 \\
\hline
\end{tabular}




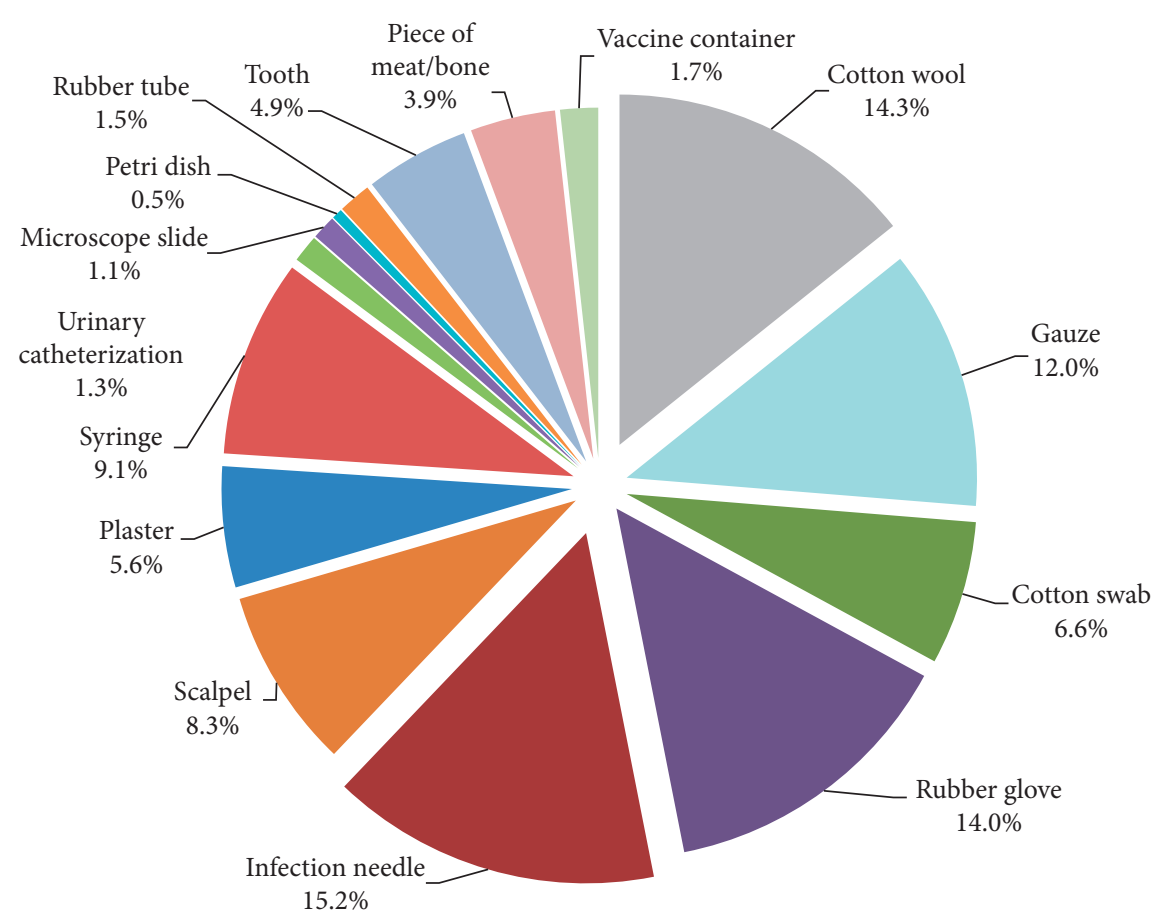

Figure 2: Composition of medical waste from clinics $(n=172)$ in Phuket Province.

George's Medical and Dental University, Lucknow, India, had good knowledge about methods of final waste disposal. From the results of this study, facts like there is no medical waste transportation service from clinics to the final disposal destination, and in Phuket, the final disposal of MW is the incinerator operated by Phuket Municipality were answered incorrectly by some doctors/dentists (50.0\% and $45.8 \%$, respectively), medical assistants/nurses/laboratory scientists (50.2\% and $62.0 \%$, respectively), and others and medical receptionists $(70.0 \%$ and $61.9 \%$, respectively). There was clearly a lack of knowledge in this area, which could lead to the respondents misunderstanding the correct methods of handling medical waste and could lead to the improper practice of discarding medical waste mixed to community garbage bins in public areas. The results from this part of the study were consistent with those from part B, which showed that $36 \%$ of the clinics who participated in this study disposed their medical waste in a public garbage container provided by the municipal waste transportation service. Therefore, relevant authorities and healthcare workers need to follow the municipal waste rules, from the segregation to the disposal processes, in particular, to their transportation and final disposal. The overall scores for the 16 items regarding knowledge of MWM were categorized into high, medium, and low levels according to Rajpal et al. [22], and the outcome is shown in Table 4.

The respondents' high level of knowledge might be because more than half of them had completed at least bachelor's degree $(67.7 \%)$ and had more than 5 years' work experience. Therefore, long-term employment in clinics may allow personnel to learn more from their working experience which could have contributed to the high level of knowledge about MWM. These findings were consistent with those of
Rao et al. [23] who discovered that most respondents (87.8\%) in a study conducted at Andhra Medical College, Visakhapatnam, India, had a high level of knowledge about handling medical waste since they had received education about medical waste management from a special agency.

3.4. Part D: Attitude of Respondents towards MWM (A). The scores relating to the attitude of the respondents to MWM are summarized (Table 5). It was found that more than $85 \%$ of the respondents had a positive attitude towards MWM, and the overall attitude score based on all the respondents' scores for the 10 attitude items (91.9\%) was categorized in the high level. Moreover, the medical receptionists, medical assistants/nurses/laboratory scientists, doctors/dentists, and other occupation groups had overall attitude scores of 95.2\%, 93.4\%, 85.4\%, and $80.0 \%$, respectively.

The responses to the items in the questionnaire showed that the majority of the respondents agreed with the statements, Medical waste generated in clinics must be handled properly (97.4\%), Gloves should always be used during medical services to prevent the hazards associated with exposure (94.2\%), and Medical waste segregation is important (86.6\%). Thus, most respondents paid attention to basic safety precautions in medical waste segregation and agreed that it was necessary to wear gloves to prevent exposure to highly hazardous waste and to control the spread of infection. The self-awareness of healthcare workers in handling medical waste is one of the most important skills that influence the quality of MWM [24]. The study of Nalwaya and Vyas [25] reported that all healthcare personnel (100\%) in Saurashtra, India, believed that safe 
TABLE 4: The responses to the items relating to the respondents' knowledge of MWM.

\begin{tabular}{|c|c|c|c|c|c|}
\hline $\begin{array}{l}\text { Knowledge of } \\
\text { MWM }\end{array}$ & $\begin{array}{l}\text { Doctors/dentists } \\
(n=48), n(\%)\end{array}$ & $\begin{array}{c}\text { Medical assistants/nurses } \\
(n=213), n(\%)\end{array}$ & $\begin{array}{l}\text { Medical receptionists } \\
\quad(n=63), n(\%)\end{array}$ & $\begin{array}{c}\text { Others }(n=20), n \\
(\%)\end{array}$ & Total \\
\hline \multicolumn{6}{|l|}{ (1) This is MW } \\
\hline \multicolumn{6}{|c|}{ (1.1) expired medicine } \\
\hline Correct & $35(72.9 \%)$ & $167(78.4 \%)$ & $50(79.4 \%)$ & $17(85.0 \%)$ & $269(78.2 \%)$ \\
\hline Incorrect & $13(27.1 \%)$ & $46(21.6 \%)$ & $13(20.6 \%)$ & $3(15.0 \%)$ & $75(21.8 \%)$ \\
\hline \multicolumn{6}{|c|}{ (1.2) Material contaminated with body fluids } \\
\hline Correct & $48(100.0 \%)$ & $204(95.8 \%)$ & $59(93.7 \%)$ & $17(85.0 \%)$ & $328(95.3 \%)$ \\
\hline Incorrect & $0(0.0 \%)$ & $9(4.2 \%)$ & $4(6.3 \%)$ & $3(15.0 \%)$ & $16(4.7 \%)$ \\
\hline \multicolumn{6}{|c|}{ (1.3) vaccine container } \\
\hline Correct & $43(89.6 \%)$ & $170(79.8 \%)$ & $50(79.4 \%)$ & $15(75.0 \%)$ & $278(80.8 \%)$ \\
\hline Incorrect & $5(10.4 \%)$ & $43(20.2 \%)$ & $13(20.6 \%)$ & $5(25.0 \%)$ & $66(19.2 \%)$ \\
\hline \multicolumn{6}{|c|}{ (2) Waste generated from healthcare activities is MW } \\
\hline Correct & $44(91.7 \%)$ & $188(88.3 \%)$ & $51(81.0 \%)$ & $8(40.0 \%)$ & $291(84.6 \%)$ \\
\hline Incorrect & $4(8.3 \%)$ & $25(11.7 \%)$ & $12(19.0 \%)$ & $12(60.0 \%)$ & $53(15.4 \%)$ \\
\hline \multicolumn{6}{|c|}{ (3) MW should not be mixed with general waste } \\
\hline Correct & $40(83.3 \%)$ & $193(90.6 \%)$ & $57(90.5 \%)$ & $15(75.0 \%)$ & $305(88.7 \%)$ \\
\hline Incorrect & $8(16.7 \%)$ & $20(9.4 \%)$ & $6(9.5 \%)$ & $5(25.0 \%)$ & $39(11.3 \%)$ \\
\hline \multicolumn{6}{|c|}{ (4) MW should be segregated immediately } \\
\hline Correct & $48(100.0 \%)$ & $202(94.8 \%)$ & $57(90.5 \%)$ & $19(95.0 \%)$ & $326(94.8 \%)$ \\
\hline Incorrect & $0(0.0 \%)$ & $11(5.2 \%)$ & $6(9.5 \%)$ & $1(5.0 \%)$ & $18(5.2 \%)$ \\
\hline \multicolumn{6}{|c|}{ (5) The color coding for MW is red } \\
\hline Correct & $46(95.8 \%)$ & $206(96.7 \%)$ & $60(95.2 \%)$ & $20(100.0 \%)$ & $332(96.5 \%)$ \\
\hline Incorrect & $2(4.2 \%)$ & $7(3.3 \%)$ & $3(4.8 \%)$ & $0(0.0 \%)$ & $12(3.5 \%)$ \\
\hline \multicolumn{6}{|c|}{ (6) The color coding for general waste is black } \\
\hline Correct & $48(100.0 \%)$ & $207(97.2 \%)$ & $61(96.8 \%)$ & $20(100.0 \%)$ & $336(97.7 \%)$ \\
\hline Incorrect & $0(0.0 \%)$ & $6(2.8 \%)$ & $2(3.2 \%)$ & $0(0.0 \%)$ & $8(2.3 \%)$ \\
\hline \multicolumn{6}{|c|}{ (7) Liquid MW should not be disposed into toilet bowl } \\
\hline Correct & $46(95.8 \%)$ & $194(91.1 \%)$ & $58(92.1 \%)$ & $17(85.0 \%)$ & $315(91.6 \%)$ \\
\hline Incorrect & $2(4.2 \%)$ & $19(8.9 \%)$ & $5(7.9 \%)$ & $3(15.0 \%)$ & $29(8.4 \%)$ \\
\hline \multicolumn{6}{|c|}{ (8) Sharp MW should be separated from other wastes } \\
\hline Correct & $41(85.4 \%)$ & $184(86.4 \%)$ & $52(82.5 \%)$ & $17(85.0 \%)$ & $294(85.5 \%)$ \\
\hline Incorrect & $7(14.6 \%)$ & $29(13.6 \%)$ & $11(17.5 \%)$ & $3(15.0 \%)$ & $50(14.5 \%)$ \\
\hline \multicolumn{6}{|c|}{ (9) MW should be put into a closed container } \\
\hline Correct & $47(97.9 \%)$ & $207(97.2 \%)$ & $62(98.4 \%)$ & $20(100.0 \%)$ & $336(97.7 \%)$ \\
\hline Incorrect & $1(2.1 \%)$ & $6(2.8 \%)$ & $1(1.6 \%)$ & $0(0.0 \%)$ & $8(2.3 \%)$ \\
\hline \multicolumn{6}{|c|}{ (10) Sharp MW must be put into a hard container } \\
\hline Correct & $47(97.9 \%)$ & $212(99.5 \%)$ & $63(100.0 \%)$ & $20(100.0 \%)$ & $342(99.4 \%)$ \\
\hline Incorrect & $1(2.1 \%)$ & $1(0.5 \%)$ & $0(0.0 \%)$ & $0(0.0 \%)$ & $2(0.6 \%)$ \\
\hline \multicolumn{6}{|c|}{ (11) MW container should be filled to no more than three-quarters full } \\
\hline Correct & $40(83.3 \%)$ & $175(82.2 \%)$ & $57(90.5 \%)$ & $10(50.0 \%)$ & $282(82.0 \%)$ \\
\hline Incorrect & $8(16.7 \%)$ & $38(17.8 \%)$ & $6(9.5 \%)$ & $10(50.0 \%)$ & $62(18.0 \%)$ \\
\hline \multicolumn{6}{|c|}{ (12) MW container should be sealed every single day } \\
\hline Correct & $33(68.8 \%)$ & $162(76.1 \%)$ & $53(84.1 \%)$ & $14(70.0 \%)$ & $262(76.2 \%)$ \\
\hline Incorrect & $15(31.2 \%)$ & $51(23.9 \%)$ & $10(15.9 \%)$ & $6(30.0 \%)$ & $82(23.8 \%)$ \\
\hline \multicolumn{6}{|c|}{ (13) There is no service for MW transportation from clinics to the final disposal destination } \\
\hline Correct & $24(50.0 \%)$ & $106(49.8 \%)$ & $36(57.1 \%)$ & $14(70.0 \%)$ & $180(52.3 \%)$ \\
\hline Incorrect & $24(50.0 \%)$ & $107(50.2 \%)$ & $27(42.9 \%)$ & $6(30.0 \%)$ & $164(47.7 \%)$ \\
\hline \multicolumn{6}{|c|}{ (14) In Phuket, the final disposal of MW is the MW incinerator operated by Phuket municipality } \\
\hline Correct & $26(54.2 \%)$ & $81(38.0 \%)$ & $24(38.1 \%)$ & $6(30.0 \%)$ & $137(39.8 \%)$ \\
\hline Incorrect & $22(45.8 \%)$ & $132(62.0 \%)$ & $39(61.9 \%)$ & $14(70.0 \%)$ & $207(60.2 \%)$ \\
\hline \multicolumn{6}{|c|}{ Categorization of the total scores from all 16 items } \\
\hline High & $41(85.4 \%)$ & $193(90.6 \%)$ & $57(90.5 \%)$ & $16(80.0 \%)$ & $308(89.5 \%)$ \\
\hline Medium & $6(12.5 \%)$ & $20(9.4 \%)$ & $6(9.5 \%)$ & $4(20.0 \%)$ & $36(10.5 \%)$ \\
\hline Low & $0(0.0 \%)$ & $0(0.0 \%)$ & $0(0.0 \%)$ & $0(0.0 \%)$ & $0(0.0 \%)$ \\
\hline
\end{tabular}

*MWM: medical waste management; MW: medical waste. 
TABLE 5: The responses to the items relating to the respondents attitude towards MWM.

\begin{tabular}{|c|c|c|c|c|c|}
\hline $\begin{array}{l}\text { Attitudes towards } \\
\text { MWM }\end{array}$ & $\begin{array}{l}\text { Doctors/dentists } \\
(n=48), n(\%)\end{array}$ & $\begin{array}{c}\text { Medical assistants/nurses } \\
(n=213), n(\%)\end{array}$ & $\begin{array}{c}\text { Medical receptionists } \\
\quad(n=63), n(\%)\end{array}$ & $\begin{array}{c}\text { Others }(n=20), n \\
(\%)\end{array}$ & Total \\
\hline \multicolumn{6}{|c|}{ (1) MW generated from clinics must be handled properly } \\
\hline Agree & $48(100.0 \%)$ & $208(97.7 \%)$ & $59(93.7 \%)$ & $20(100.0 \%)$ & $335(97.4 \%)$ \\
\hline Undecided & $0(0.0 \%)$ & $3(1.4 \%)$ & $4(6.3 \%)$ & $0(0.0 \%)$ & $7(2.0 \%)$ \\
\hline Disagree & $0(0.0 \%)$ & $2(0.9 \%)$ & $0(0.0 \%)$ & $0(0.0 \%)$ & $2(0.6 \%)$ \\
\hline \multicolumn{6}{|c|}{ (2) MW segregation is important } \\
\hline Agree & $41(85.4 \%)$ & $181(85.0 \%)$ & $57(90.5 \%)$ & $19(95.0 \%)$ & $298(86.6 \%)$ \\
\hline Undecided & $2(4.2 \%)$ & $13(6.1 \%)$ & $4(6.3 \%)$ & $0(0.0 \%)$ & $19(5.6 \%)$ \\
\hline Disagree & $5(10.4 \%)$ & $19(8.9 \%)$ & $2(3.2 \%)$ & $1(5.0 \%)$ & $27(7.8 \%)$ \\
\hline \multicolumn{6}{|c|}{ (3) Co-disposal of MW with general waste can cause unsafe effects } \\
\hline Agree & $38(79.2 \%)$ & $171(80.3 \%)$ & $51(81.0 \%)$ & $16(80.0 \%)$ & $276(80.2 \%)$ \\
\hline Undecided & $2(4.1 \%)$ & $4(1.9 \%)$ & $6(9.5 \%)$ & $3(15.0 \%)$ & $15(4.4 \%)$ \\
\hline Disagree & $8(16.7 \%)$ & $38(17.8 \%)$ & $6(9.5 \%)$ & $1(5.0 \%)$ & $53(15.4 \%)$ \\
\hline \multicolumn{6}{|c|}{ (4) MW must be collected more carefully } \\
\hline Agree & $39(81.3 \%)$ & $185(86.9 \%)$ & $55(87.3 \%)$ & $15(75.0 \%)$ & $294(85.5 \%)$ \\
\hline Undecided & $2(4.2 \%)$ & $5(2.3 \%)$ & $1(1.6 \%)$ & $0(0.0 \%)$ & $8(2.3 \%)$ \\
\hline Disagree & $7(14.5 \%)$ & $23(10.8 \%)$ & $7(11.1 \%)$ & $5(25.0 \%)$ & $42(12.2 \%)$ \\
\hline \multicolumn{6}{|c|}{ (5) General waste management and MW management are different } \\
\hline Agree & $39(81.3 \%)$ & $174(81.7 \%)$ & $52(82.5 \%)$ & $16(80.0 \%)$ & $281(81.7 \%)$ \\
\hline Undecided & $4(8.3 \%)$ & $23(10.8 \%)$ & $8(12.7 \%)$ & $1(5.0 \%)$ & $36(10.5 \%)$ \\
\hline Disagree & $5(10.4 \%)$ & $16(7.5 \%)$ & $3(4.8 \%)$ & $3(15.0 \%)$ & $27(7.8 \%)$ \\
\hline \multicolumn{6}{|c|}{ (6) Biomedical waste containers should be marked with a biohazard symbol } \\
\hline Agree & $40(83.3 \%)$ & $178(83.6 \%)$ & $55(87.3 \%)$ & $16(80.0 \%)$ & $289(84.0 \%)$ \\
\hline Undecided & $2(4.2 \%)$ & $9(4.2 \%)$ & $5(7.9 \%)$ & $0(0.0 \%)$ & $16(4.7 \%)$ \\
\hline Disagree & $6(12.5 \%)$ & $26(12.2 \%)$ & $3(4.8 \%)$ & $4(20.0 \%)$ & $39(11.3 \%)$ \\
\hline \multicolumn{6}{|c|}{ (7) Gloves should always be used during medical services to prevent the hazards associated with exposure } \\
\hline Agree & $46(95.8 \%)$ & $201(94.4 \%)$ & $61(96.8 \%)$ & $16(80.0 \%)$ & $324(94.2 \%)$ \\
\hline Undecided & $2(4.2 \%)$ & $4(1.9 \%)$ & $2(3.2 \%)$ & $2(10.0 \%)$ & $10(2.9 \%)$ \\
\hline Disagree & $0(0.0 \%)$ & $8(3.7 \%)$ & $0(0 \%)$ & $2(10.0 \%)$ & $10(2.9 \%)$ \\
\hline \multicolumn{6}{|c|}{ (8) MW management in your clinic is proper } \\
\hline Agree & $25(52.1 \%)$ & $146(68.5 \%)$ & $50(79.4 \%)$ & $11(55.0 \%)$ & $232(67.4 \%)$ \\
\hline Undecided & $16(33.3 \%)$ & $60(28.2 \%)$ & $13(20.6 \%)$ & $7(35.0)$ & $96(27.9 \%)$ \\
\hline Disagree & $7(14.6 \%)$ & $7(3.3 \%)$ & $0(0.0 \%)$ & $2(10.0 \%)$ & $16(4.7 \%)$ \\
\hline \multicolumn{6}{|c|}{ (9) MW management is your duty } \\
\hline Agree & $42(87.5 \%)$ & $155(72.8 \%)$ & $41(65.1 \%)$ & $16(80.0 \%)$ & $254(73.8 \%)$ \\
\hline Undecided & $5(10.4 \%)$ & $43(20.2 \%)$ & $16(25.4 \%)$ & $1(5.0 \%)$ & $65(18.9 \%)$ \\
\hline Disagree & $1(2.1 \%)$ & $15(7.0 \%)$ & $6(9.5 \%)$ & $3(15.0 \%)$ & $25(7.3 \%)$ \\
\hline \multicolumn{6}{|c|}{ (10) MW management must be more strictly supervised by the local government agencies } \\
\hline Agree & $37(77.1 \%)$ & $156(73.3 \%)$ & $37(58.7 \%)$ & $16(80.0 \%)$ & $246(71.5 \%)$ \\
\hline Undecided & $10(20.8 \%)$ & $55(25.8 \%)$ & $24(38.1 \%)$ & $3(15.0 \%)$ & $92(26.8 \%)$ \\
\hline Disagree & $1(2.1 \%)$ & $2(0.9 \%)$ & $2(3.2 \%)$ & $1(5.0 \%)$ & $6(1.7 \%)$ \\
\hline \multicolumn{6}{|c|}{ Categorization of the total score from all 10 items } \\
\hline High & $41(85.4 \%)$ & $199(93.4 \%)$ & $60(95.2 \%)$ & $16(80.0 \%)$ & $316(91.9 \%)$ \\
\hline Medium & $7(14.6 \%)$ & $14(6.6 \%)$ & $3(4.8 \%)$ & $4(20.0 \%)$ & $28(8.1 \%)$ \\
\hline Low & $0(0.0 \%)$ & $0(0.0 \%)$ & $0(0.0 \%)$ & $0(0.0 \%)$ & $0(0.0 \%)$ \\
\hline
\end{tabular}

*MWM: medical waste management; MW: medical waste.

disposal of biomedical waste was their duty and not an extra burden. However, in this study, most $(71.5 \%)$ but not all the respondents agreed that Clinical MWM must be more strictly supervised by local government agencies such as Phuket Municipality. Based on in-depth interviews during the survey, it was found that the majority of respondents would like public health officials to provide training and seminars about MWM related to all aspects, from waste segregation to final disposal. The importance of training regarding MWM must be over emphasized since incomplete or improper knowledge about MWM can have a negative impact on the environment.

3.5. Part E: Practice of Respondents in respect of $M W M(P)$. The respondents' practice in respect of MWM was determined in this study (Table 6), and it was found that $95.6 \%$ of the respondents answered Always to the question Do you wash your hands thoroughly after contact with medical waste, even if you wore gloves? and $93.6 \%$ of the respondents answered Always to the question Do you wear rubber gloves 
TABLE 6: The answers to questions relating to the respondents' practice in respect of MWM.

\begin{tabular}{|c|c|c|c|c|c|}
\hline $\begin{array}{l}\text { Practice in respect of } \\
\text { MWM }\end{array}$ & $\begin{array}{l}\text { Doctors/dentists } \\
(n=48), n(\%)\end{array}$ & $\begin{array}{c}\text { Medical assistants/nurses } \\
(n=213), n(\%)\end{array}$ & $\begin{array}{l}\text { Medical receptionists } \\
\quad(n=63), n(\%)\end{array}$ & $\begin{array}{c}\text { Others }(n=20), n \\
(\%)\end{array}$ & Total \\
\hline \multicolumn{6}{|c|}{ (1) How often do you separate MW from general waste? } \\
\hline Always & $39(81.3 \%)$ & $202(94.8 \%)$ & $58(92.1 \%)$ & $20(100.0 \%)$ & $319(92.7 \%)$ \\
\hline Sometimes & $2(4.2 \%)$ & $7(3.3 \%)$ & $3(4.7 \%)$ & $0(0.0 \%)$ & $12(3.5 \%)$ \\
\hline Never & $7(14.5 \%)$ & $4(1.9 \%)$ & $2(3.2 \%)$ & $0(0.0 \%)$ & $13(3.8 \%)$ \\
\hline \multicolumn{6}{|c|}{ (2) Do you put general waste into a black container and MW into a red container? } \\
\hline Always & $36(75.0 \%)$ & 192(90.1\%) & $51(81.0 \%)$ & $18(90.0 \%)$ & $297(86.3 \%)$ \\
\hline Sometimes & $4(8.3 \%)$ & $12(5.7 \%)$ & $6(9.5 \%)$ & $1(5.0 \%)$ & $23(6.7 \%)$ \\
\hline Never & $8(16.7 \%)$ & $9(4.2 \%)$ & $6(9.5 \%)$ & $1(5.0 \%)$ & $24(7.0 \%)$ \\
\hline \multicolumn{6}{|c|}{ (3) Do you wear rubber gloves during medical services? } \\
\hline Always & $44(91.7 \%)$ & $204(95.8 \%)$ & $54(85.7 \%)$ & $20(100.0 \%)$ & $322(93.6 \%)$ \\
\hline Sometimes & $4(8.3 \%)$ & $7(3.3 \%)$ & $7(11.1 \%)$ & $0(0.0 \%)$ & $18(5.2 \%)$ \\
\hline Never & $0(0.0 \%)$ & $2(0.9 \%)$ & $2(3.2 \%)$ & $0(0.0 \%)$ & $4(1.2 \%)$ \\
\hline \multicolumn{6}{|c|}{ (4) Do you not put sharp MW into a red plastic bag? } \\
\hline Always & $39(81.3 \%)$ & $171(80.3 \%)$ & $45(71.4 \%)$ & $19(95.0 \%)$ & $274(79.7 \%)$ \\
\hline Sometimes & $5(10.4 \%)$ & $10(4.7 \%)$ & $6(9.6 \%)$ & $0(0.0 \%)$ & $21(6.1 \%)$ \\
\hline Never & $4(8.3 \%)$ & $32(15.0 \%)$ & $12(19.0 \%)$ & $1(5.0 \%)$ & $49(14.2 \%)$ \\
\hline \multicolumn{6}{|c|}{ (5) Do you put sharp MW into a hard container? } \\
\hline Always & $44(91.7 \%)$ & $205(96.3 \%)$ & $61(96.8 \%)$ & $19(95.0 \%)$ & $329(95.6 \%)$ \\
\hline Sometimes & $1(2.0 \%)$ & $5(2.3 \%)$ & $2(3.2 \%)$ & $0(0.0 \%)$ & $8(2.4 \%)$ \\
\hline Never & $3(6.3 \%)$ & $3(1.4 \%)$ & $0(0.0 \%)$ & $1(5.0 \%)$ & $7(2.0 \%)$ \\
\hline \multicolumn{6}{|c|}{ (6) Do you clean spills of liquid MW immediately with proper procedure? } \\
\hline Always & $42(87.5 \%)$ & $194(91.1 \%)$ & $56(88.9 \%)$ & $17(85.0 \%)$ & $309(89.8 \%)$ \\
\hline Sometimes & $0(0.0 \%)$ & $7(3.3 \%)$ & $3(4.8 \%)$ & $0(0.0 \%)$ & $10(2.9 \%)$ \\
\hline Never & $6(12.5 \%)$ & $12(5.6 \%)$ & $4(6.3 \%)$ & $3(15.0 \%)$ & $25(7.3 \%)$ \\
\hline \multicolumn{6}{|c|}{ (7) Do you wear rubber glove when pick up trash that falls on the ground? } \\
\hline Always & $46(95.8 \%)$ & $178(83.6 \%)$ & $51(81.0 \%)$ & $19(95.0 \%)$ & $294(85.5 \%)$ \\
\hline Sometimes & $2(4.2 \%)$ & $23(10.8 \%)$ & $9(14.2 \%)$ & $1(5.0 \%)$ & $35(10.1 \%)$ \\
\hline Never & $0(0.0 \%)$ & $12(5.6 \%)$ & $3(4.8 \%)$ & $0(0.0 \%)$ & $15(4.4 \%)$ \\
\hline \multicolumn{6}{|c|}{ (8) Do you wash your hands thoroughly after contact with MW, even if you had worn gloves? } \\
\hline Always & $48(100.0 \%)$ & $202(94.8 \%)$ & $59(93.6 \%)$ & $20(100.0 \%)$ & $329(95.6 \%)$ \\
\hline Sometimes & $0(0.0 \%)$ & $4(1.9 \%)$ & $2(3.2 \%)$ & $0(0.0 \%)$ & $6(1.8 \%)$ \\
\hline Never & $0(0.0 \%)$ & $7(3.3 \%)$ & $2(3.2 \%)$ & $0(0.0 \%)$ & $9(2.6 \%)$ \\
\hline \multicolumn{6}{|c|}{ (9) Do you close and seal the MW bag when it is $1 / 3$ to $2 / 3$ full? } \\
\hline Always & $18(37.5 \%)$ & $91(42.7 \%)$ & $26(41.3 \%)$ & $5(25$ & $140(40.7 \%)$ \\
\hline Sometimes & $17(35.4 \%)$ & $45(21.1 \%)$ & $13(20.6 \%)$ & $4(20.0 \%)$ & $79(23.0 \%)$ \\
\hline Never & $13(27.1 \%)$ & $77(36.2 \%)$ & $24(38.1 \%)$ & $11(55.0 \%)$ & $125(36.3 \%)$ \\
\hline \multicolumn{6}{|c|}{ (10) Do you not reuse the plastic bag for MW? } \\
\hline Always & $28(58.3 \%)$ & $131(61.5 \%)$ & $41(65.1 \%)$ & $13(65.0 \%)$ & $213(61.9 \%)$ \\
\hline Sometimes & $13(27.1 \%)$ & $52(24.4 \%)$ & $14(22.2 \%)$ & $3(15.0 \%)$ & $82(23.8 \%)$ \\
\hline Never & $7(14.6 \%)$ & $30(14.1 \%)$ & $8(12.7 \%)$ & $4(20.0 \%)$ & $49(14.3 \%)$ \\
\hline \multicolumn{6}{|c|}{ (11) Do you collect MW and take it to a community garbage bin for transportation by Phuket Municipality? } \\
\hline Always & $20(41.7 \%)$ & $96(45.1 \%)$ & $22(34.9 \%)$ & $8(40.0 \%)$ & $146(42.5 \%)$ \\
\hline Sometimes & $6(12.5 \%)$ & $25(11.7 \%)$ & $8(12.7 \%)$ & $1(5.0 \%)$ & $40(11.6 \%)$ \\
\hline Never & $22(45.8 \%)$ & $92(43.2 \%)$ & $33(52.4 \%)$ & $11(55.0 \%)$ & $158(45.9 \%)$ \\
\hline \multicolumn{6}{|c|}{ (12) Do you not flush liquid MW into toilet bowl? } \\
\hline Always & $44(91.7 \%)$ & $179(84.0 \%)$ & $55(87.3 \%)$ & $19(95.0 \%)$ & $297(86.3 \%)$ \\
\hline Sometimes & $0(0.0 \%)$ & $10(4.7 \%)$ & $5(7.9 \%)$ & $1(5.0 \%)$ & $16(4.7 \%)$ \\
\hline Never & $4(8.3 \%)$ & $24(11.3 \%)$ & $3(4.8 \%)$ & $0(0.0 \%)$ & $31(9.0 \%)$ \\
\hline \multicolumn{6}{|c|}{ Categorization of the total score from all 12 questions } \\
\hline High & $43(89.6 \%)$ & $197(92.5 \%)$ & $58(92.1 \%)$ & $19(95.0 \%)$ & $317(92.2 \%)$ \\
\hline Medium & $5(10.4 \%)$ & $16(7.5 \%)$ & $4(6.3 \%)$ & $1(5.0 \%)$ & $26(7.5 \%)$ \\
\hline Low & $0(0.0 \%)$ & $0(0.0 \%)$ & $1(1.6 \%)$ & $0(0.0 \%)$ & $1(0.3 \%)$ \\
\hline
\end{tabular}

${ }^{*}$ MWM: medical waste management, MW: medical waste.

during medical services? Wearing gloves and hand-washing are widely recognized as practices which are effective in preventing the spread of cross-infection in healthcare facilities [26]. It is suggested that healthcare workers need to pay attention to their own health while giving services to patients. In addition, most of the respondents in this study 
(95.6\%) answered Always to the question Do you put sharp medical waste into a hard container? This finding was consistent with Gupta et al.'s finding [27] that most healthcare personnel (more than 80\%) only disposed sharps in puncture-proof containers at primary healthcare centres in Lucknow, India. The segregation of needles or other sharp medical waste is important in reducing the risk of accidental punctures or lacerations, which can contribute to the risk of infectious diseases transmission [28].

In relation to the transportation of medical waste, overall, the respondents who answered Always to Do you collect medical waste and take it to a community garbage bin for transportation by Phuket Municipality? amounted to $42.5 \%$ with the medical assistants/nurses/laboratory scientists showing the highest percentage of $45.1 \%$ and $41.7 \%$, $40.0 \%$, and $34.9 \%$, respectively, of doctors/dentists, others, and medical receptionists. The incorrect practice of mixing medical waste with community waste represents a risk to the public, especially to scavengers and garbage collectors. Based on the in-depth interviews with the respondents, a lack of understanding of the disposal methods appropriate for medical waste and general waste highlighted a need to improve the knowledge of healthcare personnel in Phuket and thus improve MWM in order to prevent negative impacts to the public and the environment. The results in this part of this study were consistent with those from part C in respect of knowledge about MWM, in which it was found that $47.7 \%$ and $60.2 \%$ of the respondents, respectively, had incorrect knowledge relating to the transportation and disposal of medical waste. However, the overall practice scores of the healthcare personnel in respect of MWM were at a very high level (92.2\%) in respect of the handling of medical waste, which was strikingly similar to the findings relating to their knowledge and attitude of $89.5 \%$ and $91.9 \%$, respectively. The findings of this study were, however, not consistent with those of the previous study of Mostafa et al. [15], which reported that the majority of doctors, nurses, and housekeepers at Al-Mansoura University Hospital, Egypt, used inadequate practices relating to MWM, with only $18.9 \%$ of the nurses, $7.1 \%$ of the housekeepers, and none of the doctors following correct practices. In addition, the study of Ismail et al. [29] found that the MWM practices were poor in all the groups of personnel surveyed at a tertiary healthcare institute in Dakshina, India, and generally, it seems that the prevalence of improper MWM practices in developing countries is alarming due to a lack of proper training and the delegation of the disposal of medical waste to poorly educated workers as discussed by Sapkota et al. [30].

3.6. Categorization of the Scores for KAP towards MWM. The respondents were classified further based on their KAP scores using the rating system aforementioned. According to the results, the respondents were included into 5 of the 8 composite rating KAP score categories (Figure 3). The results revealed that the majority of respondents (91.9\%) had high knowledge, positive attitude, and good practice $(+,+$,

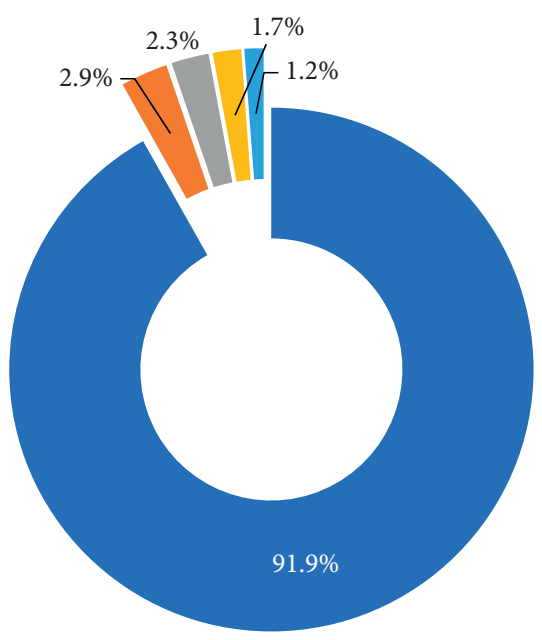

High knowledge, positive attitude, good practice

High knowledge, positive attitude, poor practice

High knowledge, negative attitude, good practice

High knowledge, negative attitude, poor practice

Low knowledge, positive attitude, good practice

FIGURE 3: The five composite KAP rating scores.

and + ). Only $2.9 \%$ of the respondents had high knowledge, positive attitude, and poor practice $(+,+$, and -$)$, and $2.3 \%$ had high knowledge, negative attitude but good practice (+, - , and +) (Figure 3). Therefore, more than $90 \%$ of the respondents in the clinics surveyed in Phuket had high/positive/good KAP $(+,+$, and +$)$ towards MWM which was in contrast to that of the study of Aluko et al. [16], who found that only $38 \%$ of healthcare workers in Nigeria had good knowledge, positive attitudes, and good perceptions $(+,+$, and + ), while $20 \%$ had poor knowledge, good attitude, and good practice $(-,+$, and +$)$.

\subsection{Correlations among Knowledge, Attitudes, and Practice in} respect of MWM. Correlation analysis among KAP in respect of MWM was conducted based on Pearson correlation coefficients, and positive and significant correlations $(P<0.01)$ were found between knowledge and attitude $(r=0.464)$, knowledge and practice $(r=0.396)$, and practice and attitude $(r=0.519)$. The moderate correlations recorded in this study can be attributed to the fairly consistently high score levels for the three aspects of the respondents' KAP. It was found that high knowledge of the personnel was associated with positive attitude and good practice towards MWM which was consistent with the classification of the KAP rating score categories, with $91.9 \%$ of the respondents showing high knowledge, positive attitude, and good practice $(+,+$, and +$)$.

No significant differences were detected for the healthcare workers grouped according to their sociodemographic characteristics with the exception that their MWM practice in respect of managing medical waste exhibited significant differences based on the duration of their working experience $(P<0.05)$, and respondents with 
more experience showed better practices (Table 2). Duration of working experience in healthcare workers is considered to be one of the most significant factors in good practice in respect of MWM, and people with longer working experience tend to have better practical and management skills in respect of MWM than those with less working experience. In this study, it was found that this was particularly the case for those with less than 2 years of working experience.

\section{Recommendations}

There is a need to focus on the control of medical waste disposal and offsite waste transportation to the final disposal destination. Local authorities should provide more training sessions for healthcare personnel who are directly involved in medical waste management in clinics and should also disseminate regulatory information, which will help personnel to understand the issue and perform their jobs properly in compliance with those regulations.

\section{Limitations of the Study}

As this study was confined to only two healthcare personnel from each clinic, more extensive studies with larger population cohort are required for better assessment the KAP in respect of MWM.

\section{Conclusions}

The current study investigated the KAP in respect of MWM of personnel in clinics in Phuket, Thailand, with the aim of contributing information useful in planning for improvements in the MWM system. The high knowledge of healthcare workers was associated with their positive attitude and good practice in respect of MWM and was consistent with their KAP rating scores categorized as high knowledge, positive attitude, and good practice. The duration of working experience of healthcare workers was the most significant factor influencing good practices related to MWM. Illegal waste disposal and the co-disposal of medical waste from clinics with municipal waste could result in a negative impact on people living in communities. However, there is only one infectious-material incineration plant available to clinics and hospitals in Phuket; therefore, investment is needed in providing safer disposal facilities to accommodate all medical waste generated from clinics and hospitals and to guarantee proper safety of the public and prevent the pollution of the environment. Finally, it is vital that policy and regulatory guidelines in respect of medical waste management should be strictly enforced by Phuket Municipality in order to improve MWM practices, especially in the collection and transportation of medical waste.

\section{Data Availability}

The data used to support the findings of this study are available from the corresponding author upon request.

\section{Conflicts of Interest}

The authors declare that there are no conflicts of interest regarding the publication of this paper.

\section{Acknowledgments}

We thank the Office of Higher Education Commission (OHEC) and the S\&T Postgraduate Education and Research Development Office (PERDO) for the financial support of the research program. We would like to express our sincere thanks to the Faculty of Technology and Environment, Prince of Songkla University, Phuket campus, Chulalongkorn University, and the Center of Excellence on Hazardous Substance Management (HSM) for their invaluable support in terms of funding, facilities, and scientific equipment. In addition, we would also like to extend our appreciation to all the study participants and the Phuket Provincial Health Office for their contribution to this study.

\section{References}

[1] S. Gary, "Clinical waste \& offensive waste disposal procedures 2016," November 2018, https://www.ucl.ac.uk/estates/sites/ estates/files/clinical-waste-procedures.pdf.

[2] US EPA, "Medical waste," November 2018, https://www.epa. gov/rcra/medical-waste.

[3] World Health Organization, "Health-care waste," November 2018, https://www.who.int/topics/medical_waste/en.

[4] K. Madhu, K. Rashmi, M. Malti, S. Geeta, and K. Reema, "Knowledge, awareness and attitude regarding biomedical waste management among medical students in a tertiary health care centre: a cross sectional study," Paripex - Indian Journal Of Research, vol. 6, no. 4, pp. 611-614, 2017.

[5] A. Tejesh, R. Geetha, V. Narendranath, and K. Ramachandra, "Assessment of knowledge, attitude, and practices regarding biomedical waste management among operation room personnel in a tertiary care Center," Journal of Anaesthesiology Clinical Pharmacology, vol. 35, no. 1, pp. 106-108, 2019.

[6] World Health Organization, "Handling, storage, and transportation of health-care waste," November 2008, https://www. who.int/water_sanitation_health/medicalwaste/061 to076.pdf.

[7] M. Azage, H. Gebrehiwot, and M. Molla, "Healthcare waste management practices among healthcare workers in healthcare facilities of Gondar town, Northwest Ethiopia," Health Science Journals, vol. 7, no. 3, pp. 315-326, 2013.

[8] S. Mohamed, S. Eva, and H. Jan-Dirk, "Hospital waste management in libya: a case study," Waste Management, vol. 29, no. 4, pp. 1370-1375, 2009.

[9] S. Tiong, P. Latiff, and S. Karuppannan, "Medical waste management in private medical clinics taiping, perak," in ICEEBS'2012, International Conference on Ecological, Environmental and Bio-Sciences, Planetary Scientific Research Centre, Pattaya, Thailand, April 2014.

[10] Tourism Authority of Thailand, "Tourist attraction places," Novembe 2018, https://www.tourismthailand.org/Destinations/ Provinces/Phuket/350.

[11] Phuket Provincial Health Office, "Guidelines for infectious waste management in phuket. prevention and suppression or dangerous substances of infectious waste," Achttp://www.phuketlocal.go.th/ files/com_news_conference/20170529141158ryzuo.pdf, Febuary 2017. 
[12] Phuket City Municipality, "Disposal of waste, Phuket province," Achttp://www.phuketcity.go.th/news_other/detail/17, January 2018.

[13] International Committee of the Red Cross, "Medical waste management," November 2018, https://www.icrc.org/eng/ assets/files/publications/icrc-002-4032.pdf.

[14] T. Yamane, Statistics: An Introductory Analysis, Harper \& Row, New York, NY, USA, 1973.

[15] G. M. Mostafa, M. M. Shazly, and W. I. Sherief, "Development of a waste management protocol based on assessment of knowledge and practice of healthcare personnel in surgical departments," Waste Management, vol. 29, no. 1, pp. 430-439, 2007.

[16] O. O. Aluko, A. E. Adebayo, T. F. Adebisi, M. K. Ewegbemi, A. T. Abidoye, and B. F. Popoola, "Knowledge, attitudes and perceptions of occupational hazards and safety practices in Nigerian healthcare workers," BMC Research Notes, vol. 9, no. 71, pp. 1-14, 2016.

[17] N. B. Pandit, H. K. Mehta, G. P. Kartha, and S. K. Choudhary, "Management of bio-medical waste: awareness and practices in a district of Gujarat," Indian Journal of Public Health, vol. 9, no. 4, pp. 245-247, 2005.

[18] J. Yong-Chul, L. Cargro, Y. Oh-Sub, and K. Hwidong, "Waste management in Korea," Journal of Environmental Management, vol. 80, no. 2, pp. 107-115, 2006.

[19] L. Vaught, "Medical waste disposal and the importance of color coding," October 2018, https://www.medsharps.com/medicalwaste-disposal-and-the-importance-of-color-coding.

[20] M. K. Abdullah and S. Al-Mukhtar, "Assessment of medical waste management in teaching hospitals in Mosul city," Mosul Nursing Journal, vol. 1, no. 1, pp. 1-8, 2013.

[21] G. P. Singh, P. Gupta, R. Kumari, and S. L. Verma, "Knowledge, attitude and practices regarding biomedical waste management among healthcare personnel in Lucknow, India," Indian Journal of Clinical Practice, vol. 24, no. 9, pp. 830-833, 2014.

[22] S. Rajpal, S. K. Garg, T. Bano, and G. Singh, "Biomedical waste management awareness in public and private hospitals in a district of North India," International Journal of Community Medicine and Public Health, vol. 5, no. 4, pp. 1499-1502, 2018.

[23] S. S. P. Rao, S. Ramani, S. Ramani, M. Raveena, and M. Nikitha, "Knowledge, attitude of medical students regarding biomedical waste management," Asian Pacific Journal of Health Sciences, vol. 3, no. 3, pp. 194-196, 2016.

[24] M. A and B. Eshwar, "Knowledge, attitude and practice of biomedical waste management among health care personnel in a tertiary care hospital in Puducherry," International Journal of Biomedical Research, vol. 6, no. 3, pp. 172-176, 2015.

[25] N. Nalwaya and R. Vyas, "Medicare for the poor in india: an ailing prescription," Health Economics and Outcome Research: Open Access, vol. 3, no. 2, Article ID 100133, 2017.

[26] J. F. Caillard, "General aspects of occupational health for healthcare workers," African Newsletter on Occupational Health and Safety, vol. 3, pp. 78-85, 1993.

[27] N. Gupta, M. Shukla, and S. Tyagi, "Knowledge, attitude and practices of biomedical waste management among health care personnel in selected primary health care centres in Lucknow," International Journal of Community Medicine and Public Health, vol. 3, no. 1, pp. 309-313, 2016.

[28] S. G. Tziaferi, P. Sourtzi, A. Kalokairinou, E. Sgourou, E. Koumoulas, and E. Velonakis, "Risk assessment of physical hazards in Greek hospitals combining staff's perception, experts' evaluation and objective measurements," Safety and Health at Work, vol. 2, no. 3, pp. 260-272, 2011.

[29] M. Ismail, G. Kulkarni, V. Kamble, A. Borker, R. Rekha, and M. Amruth, "Knowledge, attitude and practice about biomedical waste management among personnel of a tertiary health care institute in dakshina kannada, Karnataka," Journal of Medical Science, vol. 6, no. 4, pp. 376-380, 2013.

[30] B. Sapkota, K. Gupta, and D. Mainali, "Impact of intervention on healthcare waste management practices in a tertiary care governmental hospital of Nepal," BMC Public Health, vol. 14, no. 1005, 2014. 